\title{
Blockade of advanced glycation end product formation attenuates bleomycin-induced pulmonary fibrosis in rats
} \author{
Lei Chen ${ }^{\dagger 1,2}$, Tao Wang ${ }^{\dagger 1,2}$, Xun Wang ${ }^{1,2}$, Bei-Bei Sun ${ }^{1,2}$, Ji-Qiong Li1,2, Dai- \\ Shun Liu1,2, Shang-Fu Zhang ${ }^{3}$, Lin Liu ${ }^{2,4}$, Dan Xu1,2, Ya-Juan Chen ${ }^{1,2}$ and Fu- \\ Qiang Wen*1,2
}

Address: ${ }^{1}$ Division of Pulmonary Diseases, State Key Laboratory of Biotherapy of China, West China Hospital, West China School of Medicine, Sichuan University, Chengdu, Sichuan 610041, PR China, ${ }^{2}$ Department of Respiratory Medicine, West China Hospital, West China School of Medicine, Sichuan University, Chengdu, Sichuan 610041, PR China, ${ }^{3}$ Department of Pathology, West China Hospital, West China School of Medicine, Sichuan University, Chengdu, Sichuan 610041, PR China and ${ }^{4}$ Department of Respiratory Medicine, the Third People's Hospital of Mianyang, Mianyang, Sichuan 621000, PR China

Email: Lei Chen - resalex@126.com; Tao Wang - taowangwest@yahoo.com.cn; Xun Wang - wangxun.scu@163.com; BeiBei Sun - sunbaby.scu@163.com; Ji-Qiong Li - lijiqiong_scu@126.com; Dai-Shun Liu - liudaishun.scu@163.com; ShangFu Zhang - zhangshangfu@yeah.net; Lin Liu - fly1eye@163.com; Dan Xu - xudan782000@yahoo.com.cn; YaJuan Chen - chenyajuan.scu@163.com; Fu-Qiang Wen* - wenfuqiang.scu@gmail.com

* Corresponding author †Equal contributors

Published: 24 June 2009

Respiratory Research 2009, 10:55 doi:10.1186/1465-9921-10-55
Received: 29 March 2009

Accepted: 24 June 2009

This article is available from: http://respiratory-research.com/content/10/1/55

(c) 2009 Chen et al; licensee BioMed Central Ltd.

This is an Open Access article distributed under the terms of the Creative Commons Attribution License (http://creativecommons.org/licenses/by/2.0), which permits unrestricted use, distribution, and reproduction in any medium, provided the original work is properly cited.

\begin{abstract}
Background: Advanced glycation end products (AGEs) have been proposed to be involved in pulmonary fibrosis, but its role in this process has not been fully understood. To investigate the role of AGE formation in pulmonary fibrosis, we used a bleomycin (BLM)-stimulated rat model treated with aminoguanidine (AG), a crosslink inhibitor of AGE formation.
\end{abstract}

Methods: Rats were intratracheally instilled with BLM $(5 \mathrm{mg} / \mathrm{kg})$ and orally administered with AG $(40,80,120 \mathrm{mg} / \mathrm{kg})$ once daily for two weeks. AGEs level in lung tissue was determined by ELISA and pulmonary fibrosis was evaluated by Ashcroft score and hydroxyproline assay. The expression of heat shock protein 47 (HSP47), a collagen specific molecular chaperone, was measured with RTPCR and Western blot. Moreover, TGF $\beta$ I and its downstream Smad proteins were analyzed by Western blot.

Results: AGEs level in rat lungs, as well as lung hydroxyproline content and Ashcroft score, was significantly enhanced by BLM stimulation, which was abrogated by AG treatment. BLM significantly increased the expression of HSP47 mRNA and protein in lung tissues, and AG treatment markedly decreased BLM-induced HSP47 expression in a dose-dependent manner $(p<0.05)$. In addition, AG dose-dependently downregulated BLM-stimulated overexpressions of TGF $\beta$ I, phosphorylated ( $p$ )Smad2 and p-Smad3 protein in lung tissues.

Conclusion: These findings suggest AGE formation may participate in the process of BLM-induced pulmonary fibrosis, and blockade of AGE formation by AG treatment attenuates BLM-induced pulmonary fibrosis in rats, which is implicated in inhibition of HSP47 expression and TGF $\beta / S m a d s$ signaling. 


\section{Background}

Pulmonary fibrosis is a devastating disorder and no effective treatment is available now. Although the underlying molecular mechanisms of pulmonary fibrosis remain not fully understood, increased synthesis and deposition of extracellular matrix (ECM) is confirmed to be an important pathological feature of pulmonary fibrosis [1]. Advanced glycation end products (AGEs), the irreversible products of nonenzymatic glycation of proteins, nucleic acids and lipids, are increased in situations with hyperglycemia and oxidative stress, which involves a series of complex biochemical events with oxidative and nonoxidative molecular rearrangements [2,3]. Previous studies have suggested that AGEs have multiple potential effects on various disorders [2-4]. T Matsuse et al reported AGE modified proteins accumulated in alveolar macrophages in patients with idiopathic pulmonary fibrosis [5], which suggests for the first time that AGEs probably contribute to the pathogenesis of pulmonary fibrosis. However, its role in pulmonary fibrosis has not been well-elucidated.

So far, several investigators have documented AGEs can induce ECM excessive deposition and expression of heat shock protein (HSP) 47 and profibrotic cytokines, such as transforming growth factor $\beta$ (TGF $\beta$ ) 1 [6]. HSP47, a stress-inducible protein localized in the endoplasmic reticulum, is determined to play a specific role in the intracellular processing, folding, assembly and secretion of procollagens as a collagen molecular chaperone $[7,8]$. HSP47 expression is often prominent during the process of fibrosis in both humans and animal models [9-12]. In lung fibrosis, the HSP47-positive cells are considered to be the main source of collagen synthesis $[9,13]$, which suggests a potentially important role of HSP47 in the pathogenesis of pulmonary fibrosis. TGF $\beta$ is a member of a large superfamily of pleiotropic cytokines which are involved in many biological activities, including cell proliferation, differentiation, migration and apoptosis [14]. Moreover, TGF $\beta$, especially the isoform TGF $\beta 1$, is a key fibrotic stimulator in pulmonary fibrosis [15]. Generally, TGF $\beta$ performs its profibrotic effects via cascade stimulation of downstream intracellular Smad proteins. Among these Smads, Smad2 and Smad3 are necessary for TGF $\beta$ signal transduction $[14,15]$. Bleomycin (BLM), an antitumor drug, is often used to establish rodent models to mimic the pathologic features of idiopathic pulmonary fibrosis (IPF). Intratracheal instillation of bleomycin, induces pulmonary fibrosis following a gross inflammation in airways, which means a inflammatory and fibrotic phase is included in the process of BLM-induced lung injury. Time course studies have indicated the switch between the inflammatory and fibrotic phases is around day 9 after BLM treatment [16], and day 14 may be a more suitable time point for assessing lung fibrosis, considering the extensive fibrosis, but less variability in the fibrotic response and lower mortality than later time points [17]. Based on these points mentioned above, we used a rat model of pulmonary fibrosis stimulated by BLM instillation, treated with aminoguanidine (AG), an inhibitor of AGE formation by carbonyl-blocking [2], to explore whether AGE formation participates in BLM-induced pulmonary fibrosis, and whether it is involved in HSP47 expression and TGF $\beta$ signaling pathway.

\section{Methods}

\section{Animals and Reagents}

Pathogen free male Sprague-Dawley rats (250-300 g) were purchased from Experimental Animal Center of Sichuan University. Bleomycin was purchased from Harbin Bolai Pharmaceutical Co. Ltd (Harbin, China) and aminoguanidine was bought from Sigma (St. Louis, MO, USA).

\section{Treatment of Animals}

This animal study was approved by the Panel on Laboratory Animal Care of West China School of Medicine, Sichuan University. These animals were housed in the temperature $\left(22 \pm 2^{\circ} \mathrm{C}\right)$ - and humidity $(60 \pm 5 \%)$-controlled condition and kept on a 12-h light/dark cycle, with 24-h free access to the standard Purina (5001) rodent chow (autoclaved) and tap water that was heated to boiling for $20 \mathrm{~min}$ and then cooled to the room temperature before using it. Thirty rats were randomly divided into six experimental groups, with five rats per group, as follows: 1) Saline (SA)-treated with distilled water (DW) (SA group); 2) BLM-treated with DW (BLM group); 3) BLMtreated with AG $(40,80,120 \mathrm{mg} / \mathrm{kg}$ ) (BLM plus AG group); 4) SA-treated with AG (120 mg/kg) (AG group). Rats were anesthetized intraperitoneally with chloral hydrate $(3 \mathrm{ml} / \mathrm{kg})$ [18] and bleomycin $(5 \mathrm{mg} / \mathrm{kg})$ in 100 $\mu \mathrm{l}$ of saline was administered by intratracheal instillation with the same volume of saline in control animals. AG was dissolved in DW at a dose of $8 \mathrm{mg} / \mathrm{ml}$. AG or DW was administered by gavage once daily from day 1 to day 14 after BLM or saline treatment (day 0 ) and all rats were sacrificed with exsanguination on day 15 (Figure 1).

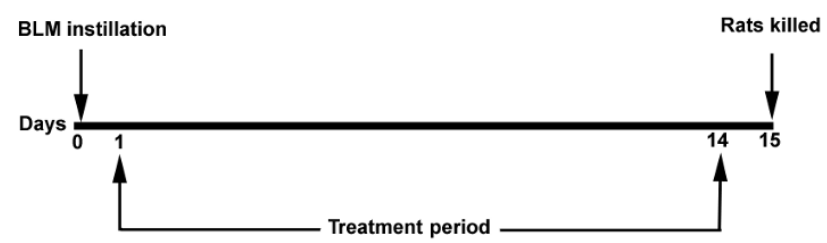

Figure I

Bleomycin administration and treatment protocol. BLM instillation was performed on day 0 . Following this, AG was administered by gavage from day I to day 14. All rats were killed on day 15. 


\section{Histopathology}

Middle lobes of right lungs were embedded in paraffin, following fixation in $10 \%$ buffering formalin, and then processed to obtain $4-\mu \mathrm{m}$ sections for Masson's trichrome staining. Histopathologic evaluation of pulmonary fibrosis was performed using Ashcroft scoring method. Briefly, the grade of lung fibrosis was scored on a scale of 0 to 8 using the following criteria: grade 0 , normal lung; grade 1 to 2, minimal fibrous thickening of alveolar or bronchiolar wall; grade 3 to 4 , moderate thickening of walls without obvious damage to lung architecture; grade 5 to 6 , increased fibrosis with definite damage to lung structure; grade 7 to 8 ; severe distortion of structure and large fibrous areas [19]. After the examination of 30 randomly chosen regions in each sample at a magnification of $\times 100$, the mean score of all the fields was taken as the fibrosis score in each sample. The scoring method strictly followed the blind principle.

\section{Hydroxyproline Assay}

To assess collagen accumulation, lung tissues (40 mg per rat lung, wet weight) were used for measurement of hydroxyproline content. Hydroxyproline assay was performed according to the instruction of hydroxyproline test kit from Nanjing Jiancheng Bioengineering Institute (Nanjing, China). In brief, frozen lung tissues were homogenized by a Polytron tissue homogenizer in saline containing $0.1 \mathrm{M}$ phenylmethylsulfonylfluoride. The homogenized sample was hydrolyzed in $6 \mathrm{~N} \mathrm{HCl}$, and the hydroxyproline concentration was determined according to the method of Otsuka et al [20].

\section{RT-PCR}

For RNA isolation, lung tissues were frozen in liquid nitrogen and stored in $-80^{\circ} \mathrm{C}$ freezer immediately. Total RNA was extracted from frozen lung tissues (left lungs) using Trizol reagent (Gibco-BRL, Gaithersburg, MD, USA), and amplified using a PCR single-step kit (Promega, USA), according to the manufacturer's instructions. RT-PCR was performed with PTC-200 DNA Engine PCR cycler (MJ Research, Inc., USA). The primers, which were designed based on published sequence of these genes and synthesized by Invitrogen (Carlsbad, CA), as follows: HSP47, forward (5'-CAAGAA CA AG GC AG AC TTATCGC-3'); reverse (5'-TCTGAT T AT CTCGCACCAGGAAG-3'), $\beta$ actin, forward (5'-C C T C A TGAAGATCCTGACCG-3'); reverse (5'-ACCGCTCA TTGCCG ATA G TG-3'). $\beta$-actin served as the constitutive control. The annealing temperature for each primer pair was $59^{\circ} \mathrm{C}$ to $\mathrm{HSP} 47$ and $58^{\circ} \mathrm{C}$ to $\beta$-actin, respectively. The products were separated by agarose gel electrophoresis and visualized by Gelview (Bioteke Corporation, Beijing, China). Semiquantitative densitometric analysis was performed with the Bio-Rad Universal Hood and Bio-Rad Quantity One software (BioRad, Hercules, CA). Means of the ratio of HSP47 band photodensity to $\beta$-actin band photodensity in various groups were presented.

\section{ELISA}

Lung tissues for ELISA were homogenized in $10 \mathrm{mM}$ Tris buffer (pH 7.4) containing 1\% Triton X-100, 1 mM EDTA, $1 \mathrm{mM}$ PMSF, $10 \mathrm{ug} / \mathrm{ml}$ aprotinin, and $10 \mathrm{ug} / \mathrm{ml}$ leupeptin. Protein concentration was quantitated by the Bicinchoninic Acid (BCA) Method according to the instruction of the BCA protein assay kit (Pierce, Rockford, IL). AGEs level in lung tissues was determined according to the instruction of the commercial ELISA kit (Uscnlife, Missouri City, TX). Samples were measured photometrically by an automated plate reader (Microplate Reader Model 1680; Bio-Rad, USA).

\section{Western Blot}

Lung homogenates were prepared in lysis buffer, containing $50 \mathrm{mM}$ Tris- $\mathrm{HCl}, 150 \mathrm{mM} \mathrm{NaCl}, 1 \% \mathrm{NP}-40,0.5 \%$ sodium deoxycholate, $2 \mathrm{mM} \mathrm{NaF}, 2 \mathrm{mM}$ EDTA, 0.1\% SDS and a protease inhibitor cocktail tablet (Roche Applied Science, Indianapolis, IN, USA). Protein concentration was quantitated by BCA Method described above. Equal amounts of protein samples $(30 \mu \mathrm{g})$ from each group were loaded onto each lane of gels. Samples and prestained molecular weight markers (Bio-Rad, Hercules, CA) were subsequently electrophoresed on $12 \%$ Tris-glycine polyacrylamide gels and then were electrophoretically transferred onto polyvinylidene difluoride (PVDF) membranes (Millipore Corp., Marlborough, MA). The membranes were blocked for $1 \mathrm{~h}$ at room temperature with $5 \%$ Bovine Serum Albumin (BSA) and were incubated overnight at $4^{\circ} \mathrm{C}$ with primary antibodies including anti-HSP47 (Santa Cruz), anti-TGF $\beta 1$ (Cell Signaling), anti-Smad2 (Cell Signaling), anti-Smad3 (Cell Signaling), anti-pSmad2 (Cell Signaling), anti-p-Smad3 (Cell Signaling), and anti- $\beta$-actin (Santa Cruz), at a dilution of 1:1000 in Tris-buffered saline with Tween-20 (TBST). $\beta$-actin served as the constitutive control to confirm equal amounts of protein loading. After washing with TBST, the membranes were incubated with the corresponding horseradish peroxidase-linked antirabbit antibody (Pierce, Rockford, IL) diluted 1:20000 in TBST for $1 \mathrm{~h}$ at room temperature. After further washing with TBST, immunoreactive bands were visualized by enhanced chemiluminescence (ECL), and quantified by densitometry with the Bio-Rad Universal Hood and Quantity One software (Bio-Rad). All results were normalized to $\beta$-actin levels in each lane.

\section{Statistical Analysis}

All values were expressed as means \pm standard deviation (SD). One-way ANOVA followed by Student-NewmanKeuls test was used to compare the differences among multiple groups. Significance was defined by a P value of 
0.05. SPSS 13.0 software package (SPSS, Inc., Chicago, IL) was used for statistical analysis.

\section{Results}

AGEs level as well as bleomycin-induced pulmonary fibrosis is attenuated by AG treatment

Bleomycin instillation significantly induced pulmonary fibrosis (Figure 2A). Compared with the SA group, AGEs level in lung tissues was markedly increased in the BLM group ( $\mathrm{p}<0.01$; Figure $2 \mathrm{~B}$ ), and was dose-dependently decreased with AG treatment, similar to the changes of Ashcroft score and lung hydroxyproline content (Figure 2C, D), which were used for assessing the degree of pul- monary fibrosis. Masson staining of lung specimens demonstrated that bleomycin instillation induced severe distortion of lung structure and accumulation of collagen fiber (blue) in rat lungs, whereas a well-alveolized normal histology was seen in rats treated with saline (Figure 2A). The histopathological characteristics of the SA group were not significantly different from those of the AG group. AG treatment significantly attenuated bleomycin-induced fibrotic lesions and collagen fiber accumulation in rat lungs in a dose-dependent manner. To confirm the effect of AG on the histopathological change of bleomycininduced pulmonary fibrosis, the overall grades of the fibrotic changes of the lungs were performed by Ashcroft
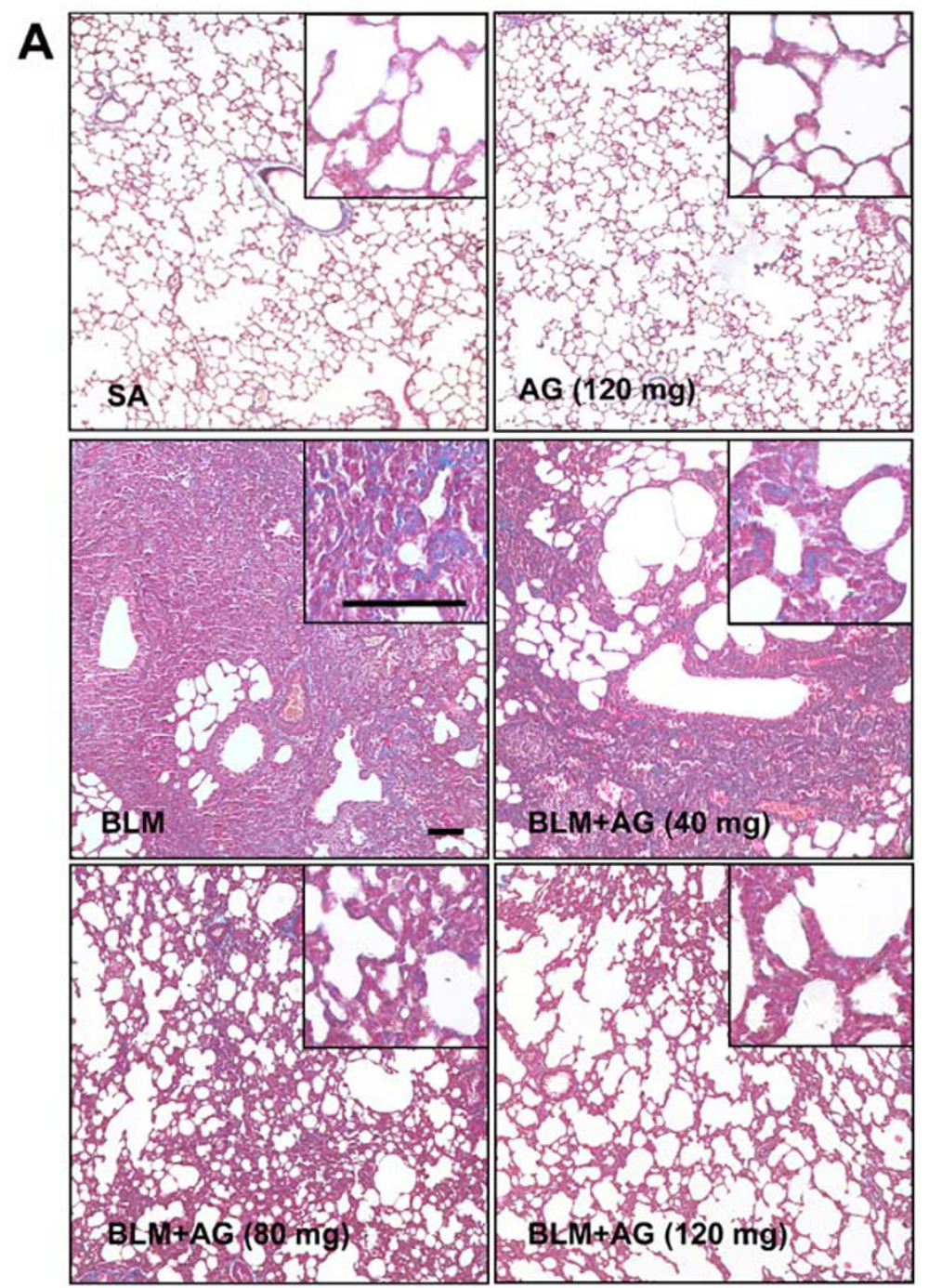

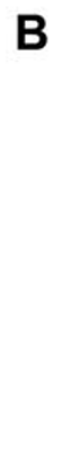

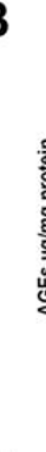

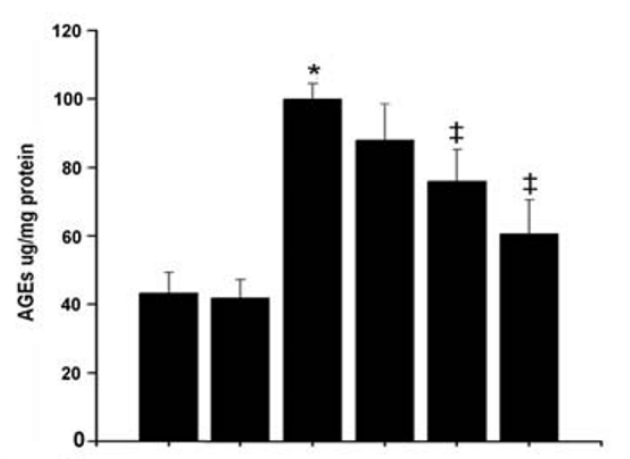

C

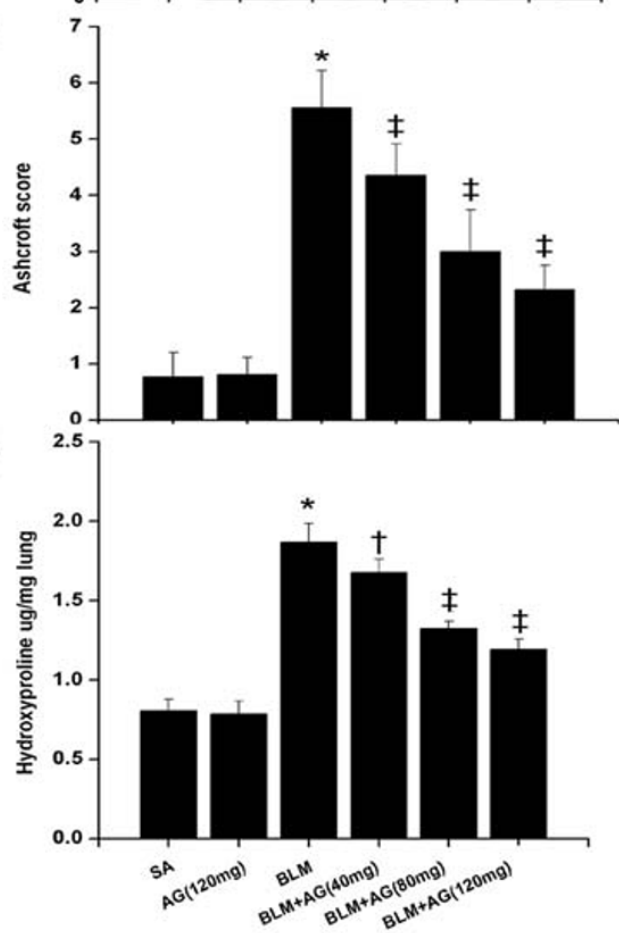

\section{Figure 2}

Effect of AG on AGEs level and bleomycin-induced pulmonary fibrosis. (A) Shown are representative photomicrographs of Masson-stained sections of lung tissues from each group. Collagens were stained blue. Bar $=100 \mu \mathrm{m}$. Comparisons of AGEs level (B), Ashcroft score (C) and lung hydroxyproline content (D) among different experimental groups were presented. Data represent mean $\pm S D, n=5$ in each group, ${ }^{*}<0.01$ vs SA group; $\dagger p<0.05$ vs BLM group; $\ddagger p<0.01$ vs BLM group. 
score (Figure 2C). The score of the BLM+AG group was significantly lower than that of the BLM group $(\mathrm{p}<0.01)$.

Collagen deposition in lung tissues was assessed by measuring the hydroxyproline content. Compared with the SA group, hydroxyproline content was significantly increased in the BLM group after bleomycin infusion. The increased hydroxyproline content in rat lungs was decreased dosedependently with AG administration ( $\mathrm{p}<0.05$; Figure 2D). However, no significant differences were observed in levels of AGEs, Ashcroft score, and lung hydroxyproline content between the SA and AG groups.

\section{HSP47 mRNA and protein overexpressions in lung tissues} induced by bleomycin are inhibited by AG treatment HSP47 mRNA expression in rat lungs was measured by RT-PCR. The expression of HSP47 mRNA in the BLM group was much higher than control rats in the SA group ( $\mathrm{p}<0.01)$. AG treatment significantly inhibited BLMinduced HSP47 mRNA expression in lung tissues ( $\mathrm{p}<$ $0.05, \mathrm{p}<0.01$; Figure 3 ). This inhibitory effect was in a
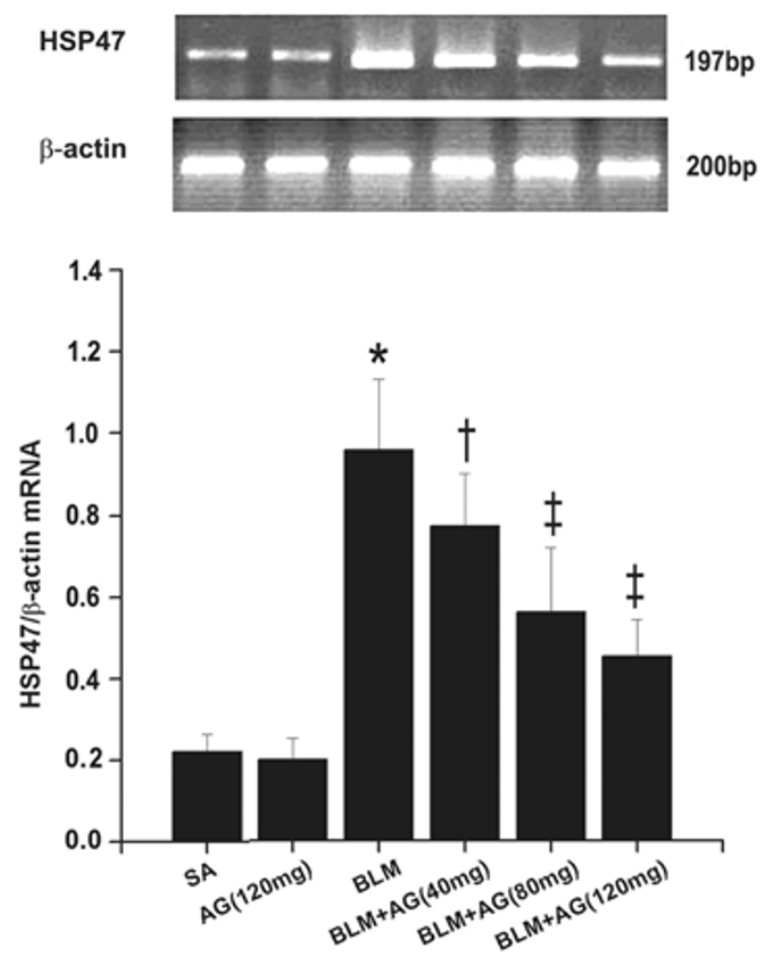

Figure 3

Effect of AG on bleomycin-induced HSP47 mRNA expression. The expression of HSP47 mRNA was measured by RT-PCR. The mean ratios of photodensity of HSP47 band to that of $\beta$-actin control were shown. Data represent mean $\pm S D, n=5$ in each group, ${ }^{*} p<0.0$ I vs SA group; $\dagger p<0.05$ vs $B L M$ group; $\ddagger P<0.01$ vs BLM group. dose-dependent manner. Meanwhile, BLM stimulation significantly increased HSP47 protein expression in rat lungs ( $\mathrm{p}<0.01$ ), which was inhibited by AG treatment dose-dependently ( $p<0.05, p<0.01$; Figure 4A, B). These changes in the Western blot were in accordance with the findings in the RT-PCR study. No significant changes of HSP47 mRNA and protein were revealed in the SA and AG groups.

TGF $\beta$ I, p-Smad2, p-Smad3 protein expressions in lung tissues after bleomycin stimulation are downregulated by AG treatment

As a key factor of pulmonary fibrosis, TGF $\beta 1$ was determined by Western blot. BLM significantly increased TGF $\beta 1$ protein expression in lung tissues $(\mathrm{p}<0.01)$, which was downregulated by AG treatment dose-dependently ( $\mathrm{p}<0.01$; Figure 4A, C). No significant difference was revealed in TGF $\beta 1$ expression level between the SA and AG groups.

Because phosphorylation of Smad signaling by the activated TGF $\beta 1$ receptor $I$ is a major step in the initiation of TGF $\beta 1$ signal transduction, we further examined whether Smad2 and Smad3 phosphorylation in bleomycininduced pulmonary fibrosis was changed by AG treatment. Immunoblot analysis showed a marked increase in Smad2 and Smad3 phosphorylation in the BLM lungs over the SA lungs after bleomycin treatment $(\mathrm{p}<0.01)$. AG administration dose-dependently reduced the phosphorylation of Smad2 and Smad3 protein in the bleomycin-induced pulmonary fibrosis $(\mathrm{p}<0.05, \mathrm{p}<0.01$; Figure $4 \mathrm{~A}, \mathrm{D}, \mathrm{E})$. However, there were no significant changes in total Smad2 and Smad3 expressions among experimental groups (Figure 4A), and no significant differences were observed in Smad2 and Smad3 phosphorylation between the SA group and AG group.

\section{Discussion}

In the present study, BLM stimulation markedly increased the level of AGEs in lung tissues as well as lung hydroxyproline content and fibrosis score, which were inhibited with treatment of $\mathrm{AG}$, an AGE formation inhibitor, in a dose-dependent manner. Further, AG treatment also decreased BLM-induced HSP47 expression, downregulated TGF $\beta 1, \mathrm{p}-\mathrm{Smad} 2$ and $\mathrm{p}-\mathrm{Smad} 3$ expressions, and subsequently attenuated BLM-induced pulmonary fibrosis. From these findings, we conclude that AGEs may play an important role in pulmonary fibrosis induced by BLM, which may be involved in its potentially regulatory effects on HSP47 expression and TGF $\beta /$ Smads signaling pathway.

Prior studies have strongly evidenced the positive roles of AGEs in the process of fibrogenesis. Huang et al and Lee et al reported AGE dose- and time-dependently increased 
A

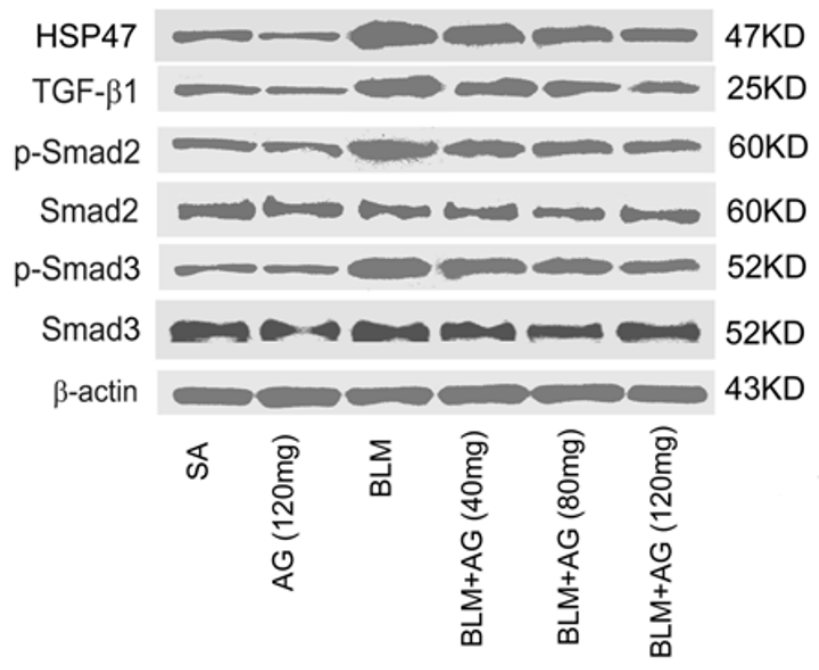

B
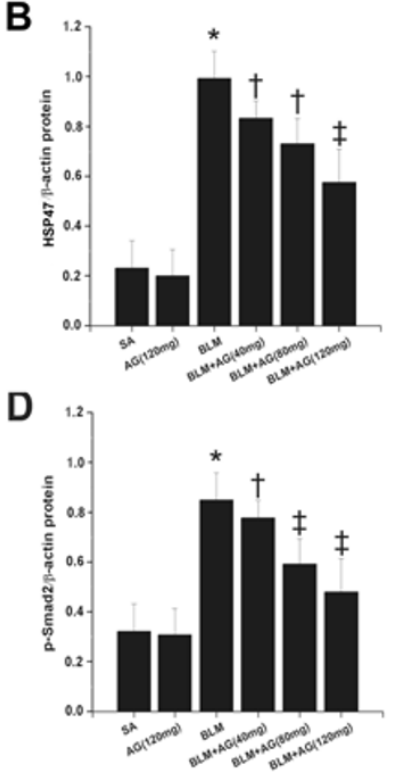

C

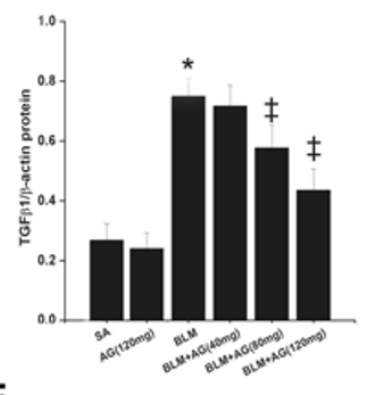

E

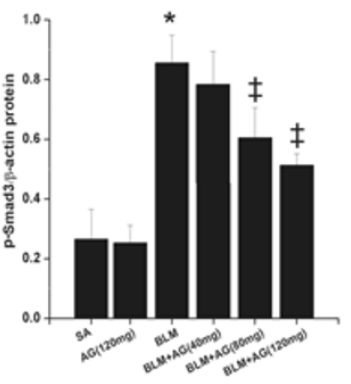

\section{Figure 4}

Effect of AG on HSP47, TGF $\beta$ I, p-Smad2, Smad2, p-Smad3 and Smad3 protein after bleomycin instillation.

Western blot was performed to determine the expression levels of target proteins. (A) Representative blotting images of HSP47, TGF 3 I, p-Smad2, Smad2, p-Smad3, Smad3, and $\beta$-actin were shown. Densitometric analysis of HSP47 (B), TGF $\beta$ I (C), $\mathrm{p}$-Smad2 (D), p-Smad3 (E) protein expression relative to the $\beta$-actin control was presented. Data represent mean $\pm S D, n=5$ in each group, $* p<0.01$ vs SA group; $\dagger p<0.05$ vs BLM group; $\ddagger p<0.01$ vs BLM group.

collagen production and connective tissue growth factor (CTGF) mRNA and protein expression in NRK-49F (normal rat kidney fibroblast) cells $[21,22]$. In human foreskin fibroblasts, Lohwasser et al found AGE incubation could increase CTGF, TGF- $\beta 1$, and procollagen-alpha1 (I) mRNA [23]. Futher more, AGE treatment significantly increased fibronectin and type IV collagen accumulation in renal glomeruli, and also markedly induced renal TGF$\beta 1$ and CTGF expression in rats [24]. These in-vitro and invivo experimental studies indicate AGEs could be an effective stimulator in fibrogenesis. In the present study, our data confirm AGEs accumulation is paralleled with the progression of BLM-induced pulmonary fibrosis assessed by lung hydroxyproline assay and fibrotic scoring, and blockade of AGE formation by AG treatment significantly attenuates BLM-induced pulmonary fibrosis, which supports the participation of AGE formation in this process.

As excessive deposition of ECM may contribute to pulmonary fibrosis [1] and collagens are the major fibrous proteins in ECM, we considered AGEs could have effects on collagen synthesis within the process of pulmonary fibrosis. HSP47, as a specific collagen molecular chaperone, was reported to be correlated well with collagen deposition in both animal and human studies [25-27], which suggests an important role of HSP47 in increased deposition of collagens during the progression of fibrotic dis- eases. Moreover, recent researches by Hagiwara and his colleagues reported that inhibition of HSP47 by antisense oligodeoxynucleotides significantly suppressed the production of collagen and subsequently attenuated pulomonary fibrosis in bleomycin-, lipopolysaccharide- and paraquat-induced pulmonary fibrosis in rats [28-30]. These findings further demonstrate a key role of HSP47 in collagen synthesis during the course of pulmonary fibrosis. The present results show overexpression of HSP47 induced by BLM is dose-dependently inhibited by AG treatment, which indicates that AGE formation may participate in BLM-stimulated pulmonary fibrosis at least partly through upregulation of HSP47 expression, and HSP47 may be a critical target factor of AGEs in BLMinduced pulmonary fibrosis. But so far very little is known about the underlying molecular mechanism by which AGE formation modulates HSP47 expression in BLMstimulated pulmonary fibrosis.

It has been well-documented that TGF $\beta 1$ appears to be the predominant isoform of TGF $\beta$ s involved in pulmonary fibrosis, which exerts its profibrotic effects through chemoattraction and stimulation of fibroblasts to express growth factors and extracellular matrix components [8]. Several reporters demonstrated TGF $\beta 1$, as a major regulator, stimulated HSP47 expression, in parallel with collagen production [26,31-33]. Simultaneously, as was also 
reported, AGEs could increase both TGF $\beta 1$ and HSP47 expression in cultured mesangial cells [6]. Although there are no direct evidences to determine whether TGF $\beta$ signaling contributes to AGE induction of HSP47 expression, Li and his colleagues reported AGE induced a rapid Smad2 and Smad3 nuclear translocation and phosphorylation by normal rat tubular epithelial cells, glomerular mesangial cells, and vascular smooth muscle cells in a dose- and time-dependent manner, which was mediated by TGF $\beta$ signaling pathway [34], and Ohashi et al further found mesangial cells transfected with Smad1-antisense oligomers showed much less expression of HSP47 and type IV collagen transcripts after AGE stimulation than those with control oligomers [6]. These studies indicate TGF $\beta /$ smads might play an important role in the process of AGEinduced HSP47 expression. So, we hypothesised the potentially regulatory effect of AGEs on BLM-induced HSP47 expression was involved in TGF $\beta /$ smads pathway. In our study, through inhibition of AGE formation in BLM-induced lung fibrosis by AG treatment, the expressions of TGF $\beta 1$, p-Smad2 and p-Smad3 were all downregulated dose-dependently, suggesting TGF $\beta /$ Smads signaling pathway probably plays a role in AGE-regulated HSP47 expression induced by BLM, although this link still needs more evidences to confirm.

Taken together, our results demonstrate AGE formation contributes to BLM-stimulated lung fibrosis, and HSP47 may be a potential target factor of AGEs. Blockade of AGE formatioin by AG treatment attenuates BLM-induced HSP47 overexpression, probably through inhibition of TGF $\beta 1 /$ Smad2/Smad3 signaling pathway, which suggests for the first time that AGEs may participate in the process of BLM-induced pulmonary fibrosis, at least partly implicated in TGF $\beta /$ Smads-HSP47 pathway. The further study should focus on whether the contribution of AGEs to the lung fibrosis is involved in its receptor, the receptor of AGEs (RAGE). In recent studies, loss of RAGE was observed in the lungs of IPF patients and bleomycin- or asbestos-treated rats [35,36]. In addition, RAGE-null mice developed more severe pulmonary fibrosis than wild-type controls [35], indicative of a protective role of RAGE in lung fibrosis. However, He et al demonstrated that RAGE contributed to bleomycin-induced lung fibrosis through epithelial-mesenchymal transition and profibrotic cytokine production [37]. It can be seen the role of RAGE in pulmonary fibrosis needs further determination.

\section{Conclusion}

AGEs are complex products of nonenzymatic glycation, with links to fibrotic lesions in various disorders. Our findings firstly demonstrate AGE formation may participate in BLM-induced pulmonary fibrosis, and TGF $\beta /$ Smads-HSP47 pathway is probably implicated in this process, although more investigations are needed to con- firm this mechanism. Moreover, the inhibitory effect of AG on HSP47 expression and TGF $\beta /$ smads signaling pathway in BLM-induced pulmonary fibrosis, is supposed to be a beneficial supplement for more understanding of the protective role of AG in BLM-induced pulmonary fibrosis.

\section{Abbreviations}

$A G$ : aminoguanidine; $A G E(s)$ : advanced glycation end product(s); BLM: bleomycin; CTGF: connective tissue growth factor; $D W$ : distilled water; ECM: Extracellular matrix; ELISA: Enzyme-Linked ImmunoSorbent Assay; HSP47: heat shock protein 47; p-Smad2/3: phosphorylated-Smad2/Smad3; RAGE: receptor of advanced glycation end products; RT-PCR: Reverse TranscriptasePolymerase Chain Reaction; TGF $\beta 1$ : transforming growth factor $\beta 1 ; S A$ : saline; $S D$ : standard deviation.

\section{Competing interests}

The authors declare that they have no competing interests.

\section{Authors' contributions}

LC and TW drafted the manuscript, and LC carried out the data analysis. FW was responsible for the design of the original study. LC, TW and DL participated in the design of animal experiment. LC, XW, BS, JL, LL and YC carried out the animal experiment. LC, TW, SZ and DX carried out the fibrosis score, RT-PCR, Western blot, ELISA, Masson stain and hydroxyproline content assays.

\section{Acknowledgements}

This study was supported by grants \#30425007, 30370627, 3067092I from National Natural Science Foundation of China and 00-722, 06-834 from China Medical Board of New York, and Research Fund for the Doctoral Program of Higher Education and the Scientific Research Foundation for the Returned Overseas Chinese Scholars from Ministry of Education, PR China to Dr. F.Q. Wen.

\section{References}

I. Cook DN, Brass DM, Schwartz DA: A Matrix for New Ideas in Pulmonary Fibrosis. Am J Respir Cell Mol Biol. 2002, 27(2): I22-124.

2. Ulrich P, Cerami A: Protein glycation, diabetes, and aging. Recent Prog Horm Res 200I, 56:I-2I.

3. Bohlender JM, Franke S, Stein G, Wolf G: Advanced glycation end products and the kidney. Am J Physiol Renal Physiol 2005, 289:F645-F659.

4. Ramasamy R, Vannucci SJ, Yan SS, Herold K, Yan SF, Schmidt AM: Advanced glycation end products and RAGE: a common thread in aging, diabetes, neurodegeneration, and inflammation. Glycobiology. 2005, I5(7): I6R-28R.

5. Matsuse T, Ohga E, Teramoto S, Fukayama M, Nagai R, Horiuchi S, Ouchi Y: Immunohistochemical localisation of advanced glycation end products in pulmonary fibrosis. J Clin Pathol. 1998, 5I(7):5I5-5I9.

6. Ohashi S, Abe H, Takahashi T, Yamamoto Y, Takeuchi M, Arai H, Nagata K, Kita T, Okamoto H, Yamamoto H, Doi T: Advanced Glycation End Products Increase Collagen-specific Chaperone Protein in Mouse Diabetic Nephropathy. J Biol Chem. 2004, 279(19): 19816-19823.

7. Dafforn TR, Della M, Miller AD: The molecular interactions of heat shock protein 47 (Hsp47) and their implications for collagen biosynthesis. J Biol Chem. 200I, 276(52):493 I0-493I9. 
8. Nakai A, Satoh M, Hirayoshi K, Nagata K: Involvement of the stress protein HSP47 in procollagen processing in the endoplasmic reticulum. J Cell Biol. 1992, I I 7(4):903-914.

9. Ishii H, Mukae H, Kakugawa T, Iwashita T, Kaida H, Fujii T, Hayashi T, Kadota J, Kohno S: Increased expression of collagen-binding heat shock protein 47 in murine bleomycin-induced pneumopathy. Am J Physiol Lung Cell Mol Physiol. 2003, 285(4):L957-L963.

10. Abe K, Ozono Y, Miyazaki M, Koji T, Shioshita K, Furusu A, Tsukasaki S, Matsuya F, Hosokawa N, Harada T, Taguchi T, Nagata K, Kohno S: Interstitial expression of heat shock protein 47 and alphasmooth muscle actin in renal allograft failure. Nephrol Dial Transplant 2000, 15:529-535.

II. Shioshita K, Miyazaki M, Ozono Y, Abe K, Taura K, Harada T, Koji T, Taguchi T, Kohno S: Expression of heat shock proteins 47 and 70 in the peritoneum of patients on continuous ambulatory peritoneal dialysis. Kidney Int 2000, 57:619-63I.

12. Razzaque MS, Taguchi T: The possible role of colligin/HSP47, a collagen-binding protein, in the pathogenesis of human and experimental fibrotic diseases. Histol Histopathol. 1999, 14(4): I199-1212.

13. Iwashita T, Kadota J, Naito S, Kaida H, Ishimatsu Y, Miyazaki M, Ozono Y, Kohno S: Involvement of collagen-binding heat shock protein 47 and procollagen type I synthesis in idiopathic pulmonary fibrosis: contribution of type II pneumocytes to fibrosis. Hum Pathol 2000, 3 I: I 498-I505.

14. Ulrike B, Christian PS: The Role of Transforming Growth Factor $\beta$ in Lung Development and Disease. Chest 2004, 1 25:754-765.

15. Leask $A$, Abraham DJ: TGF- $\beta$ signaling and the fibrotic response. The FASEB Journal 2004, 18:816-827.

16. Izbicki G, Segel MJ, Christensen TG, Conner MW, Breuer R: Time course of bleomycin induced lung fibrosis. Int J Exp Path 2002, 83: III-II9.

17. Chaudhary NI, Schnapp A, Park JE: Pharmacologic Differentiation of Inflammation and Fibrosis in the Rat Bleomycin Model. Am J Respir Crit Care Med 2006, 173:769-776.

18. Wang T, Liu Y, Chen L, Wang X, Hu XR, Feng YL, Liu DS, Xu D, Duan $Y P$, Lin J, Ou XM, Wen FQ: Effect of sildenafil on acroleininduced airway inflammation and mucus production in rats. Eur Respir J 2009, 33: I I 22-1 I 32

19. Ashcroft T, Simpson JM, Timbrell V: Simple method of estimating severity of pulmonary fibrosis on a numerical scale. J Clin Pathol 1988, 41:467-470.

20. Otsuka M, Takahashi H, Shiratori M, Chiba H, Abe S: Reduction of bleomycin induced lung fibrosis by candesartan cilexetil, an angiotensin II type I receptor antagonist. Thorax 2004, 59:3I-38.

21. Huang JS, Guh JY, Chen HC, Hung WC, Lai YH, Chuang LY: Role of receptor for advanced glycation end product (RAGE) and the JAK/STAT-signaling pathway in AGE-induced collagen production in NRK-49F cells. J Cell Biochem 2001, 81:102-1 I3.

22. Lee $\mathrm{Cl}$, Guh JY, Chen HC, Lin KH, Yang YL, Hung WC, Lai YH, Chuang LY: Leptin and connective tissue growth factor in advanced glycation end product-induced effects in NRK-49F cells. J Cell Biochem 2004, 93(5):940-50.

23. Lohwasser C, Neureiter D, Weigle B, Kirchner T, Schuppan D: The receptor for advanced glycation end products is highly expressed in the skin and upregulated by advanced glycation end products and tumor necrosis factor-alpha. J Invest Dermatol 2006, I 26(2):29|-9.

24. Zhou GH, Li C, Cai L: Advanced glycation end products induce connective tissue growth factor-mediated renal fibrosis predominantly through transforming growth factor beta independent pathway. Am J Pathol. 2004, I 65(6):2033-2043.

25. Razzaque MS, Nazneen A, Taguchi T: Immunolocalization of collagen and collagen-binding heat shock protein 47 in fibrotic lung diseases. Mod Pathol. 1998, I I(I 2): I I83-I I88.

26. Razzaque MS, Ahmed AR: Collagens, collagen-binding heat shock protein 47 and transforming growth factor-beta I are induced in cicatricial pemphigoid: possible role(s) in dermal fibrosis. Cytokine 2002, I 7(6):311-6.

27. Hagiwara S, Iwasaka H, Matsumoto S, Noguchi T, Yoshioka H: Coexpression of HSP47 gene and type I and type III collagen genes in LPS-induced pulmonary fibrosis in rats. Lung 2007, 185(I):3I-7.
28. Hagiwara S, Iwasaka H, Matsumoto S, Noguchi T: Antisense oligonucleotide inhibition of heat shock protein (HSP) 47 improves bleomycin-induced pulmonary fibrosis in rats. Respir Res 2007, 8:37.

29. Hagiwara S, Iwasaka H, Matsumoto S, Noguchi T: Introduction of antisense oligonucleotides to heat shock protein 47 prevents pulmonary fibrosis in lipopolysaccharide-induced pneumopathy of the rat. Eur J Pharmacol 2007, 564(I-3): I74-80.

30. Hagiwara S, Iwasaka H, Matsumoto S, Noguchi T: An antisense oligonucleotide to HSP47 inhibits paraquat-induced pulmonary fibrosis in rats. Toxicology 2007, 236(3): 199-207.

31. Pan H, Halper J: Regulation of heat shock protein 47 and type I procollagen expression in avian tendon cells. Cell Tissue Res. 2003, 3 I I (3):373-382.

32. Rocnik E, Chow LH, Pickering JG: Heat Shock Protein 47 Is Expressed in Fibrous Regions of Human Atheroma and Is Regulated by Growth Factors and Oxidized Low-Density Lipoprotein. Circulation. 2000, I0 I (I I):I229-I233.

33. Sasaki H, Sato T, Yamauchi N, Okamoto T, Kobayashi D, lyama S, Kato J, Matsunaga T, Takimoto R, Takayama T, Kogawa K, Watanabe N, Niitsu Y: Induction of Heat Shock Protein 47 Synthesis by TGF- $\beta$ and IL-I $\beta$ Via Enhancement of the Heat Shock Element Binding Activity of Heat Shock Transcription Factor I. J Immunol 2002, 168:5I78-5183.

34. Li JH, Huang XR, Zhu HJ, Oldfield M, Cooper M, Truong LD, Johnson RJ, Lan HY: Advanced glycation end products activate Smad signaling via TGF- $\beta$-dependent and -independent mechanisms: implications for diabetic renal and vascular disease. FASEB ]. 2004, I8(I): I76-178.

35. Englert JM, Hanford LM, Kaminski N, Tobolewski JM, Tan RJ, Fattman CL, Ramsgaard L, Richards TJ, Loutaev I, Nawroth PP, Kasper M, Bierhaus A, Oury TD: A Role for the Receptor for Advanced Glycation End Products in Idiopathic Pulmonary Fibrosis. Am J Pathol. 2008, I 72(3):583-59|.

36. Queisser MA, Kouri FM, Königshoff M, Wygrecka M, Schubert U, Eickelberg O, Preissner KT: Loss of RAGE in Pulmonary Fibrosis: Molecular Relations to Functional Changes in Pulmonary Cell Types. J Respir Cell Mol Biol. 2008, 39(3):337-345.

37. He M, Kubo H, Ishizawa K, Hegab AE, Yamamoto $Y$, Yamamoto $H$, Yamaya M: The role of the receptor for advanced glycation end-products in lung fibrosis. Am J Physiol Lung Cell Mol Physiol. 2007, 293(6):LI427-LI436.

Publish with BioMed Central and every scientist can read your work free of charge

"BioMed Central will be the most significant development for disseminating the results of biomedical research in our lifetime."

Sir Paul Nurse, Cancer Research UK

Your research papers will be:

- available free of charge to the entire biomedical community

- peer reviewed and published immediately upon acceptance

- cited in PubMed and archived on PubMed Central

- yours - you keep the copyright

Submit your manuscript here:

http://www.biomedcentral.com/info/publishing_adv.asp
BioMedcentral 